\title{
¿POR QUÉ MARCHAN LOS ESTUDIANTES EN CHILE?: DISCURSO ELECTRÓNICO Y PODER EN UN CIBERPERIÓDICO CHILENO
}

\author{
(¿Why do students march in Chile? Electronic discourse and \\ power in a Chilean cyber newspaper)
}

Lésmer Antonio Montecino Soto ${ }^{1}$

\begin{abstract}
In the framework of Critical Discourse Analysis (CDA), this essay aims to give an account on the arguments posted by readers in the blog of a Chilean cyber newspaper, with the purpose of expressing their opposition towards the student movement. Through the different topoi, bloggers reproduce the discourse of power related to a model of society and education generated by the neoliberal system prevailing in Chile. This economic model, in the Chilean socio-cultural context, has only brought about, inequality and impoverishment.
\end{abstract}

Keywords: cyber newspaper, critical discourse analysis, ideology, topoi.

\section{RESUMO}

No enquadre da Análise de Discurso Crítica (ADC), este artigo tem como objetivo discutir argumentos utilizados por leitores/as do blog de um ciberperiódico chileno, nos comentários que enviaram a fim de manifestar sua oposição ao movimento estudantil. Por meio de diversos topoi, reproduzem o discurso do poder, que se vincula a um modelo de sociedade

1. Profesor Asociado, Facultad de Letras, Pontificia Universidad Católica de Chile. Dr. en Lingüística, Universidad de Valladolid, España. Especialización: Análisis del Discurso, Análisis Crítico del Discurso, Pragmática, Lingüística del Texto, y Español para Extranjeros. Investiga en los ámbitos de la cortesía en el español de Chile y del Análisis Crítico del Discurso. En este contexto, ha sido co-investigador en el proyecto FONDECYT No 1060566 (2006-2008) "Encuentros orales con fines de estudio" e investigador responsable del proyecto FONDECYT N 1071094 (20072009) "El discurso de las personas en situación de calle en Santiago de Chile". Miembro del Grupo ECLAR (Español de Chile y de Argentina), de REDLAD (Red Latinoamericana de Análisis Crítico del Discurso de la Pobreza en América Latina) y de la Asociación Latinoamericana de Estudios del Discurso ALED. 
e de educação próprios do sistema neoliberal. No contexto sociocultural chileno, esse modelo tem gerado desigualdade e empobrecimento.

Palavras-chave: ciberperiódico, análise de discurso crítica, ideologia, topoi.

\section{Introducción}

En la actualidad, cada diario en línea o ciberperiódico a diferencia de su formato en papel, utiliza todos los recursos que posibilitan una interacción dinámica gracias a recursos tales como el video, audio, imágenes, gráficos, diagramación, publicidad interactiva, etc. No obstante, mantiene los géneros propios del discurso periodístico: editorial, columna, noticias, reportajes, etc.

De los géneros mencionados, me interesan el editorial y la columna en cuanto textos que motivan la interactividad a través de la participación de los lectores en los blogs con sus comentarios. En otras palabras, tanto el editorial como la columna promueven una interactividad que se traduce en comentarios sobre los temas que los medios en línea ponen en la agenda. Generalmente quienes escriben columnas y editoriales lo hacen sobre educación, salud, vivienda, corrupción, delincuencia, drogas, seguridad ciudadana, entre otros temas que, de acuerdo con el acontecer de nuestra sociedad en vías de desarrollo, están siempre en la agenda.

Tal como se presentan los tópicos, parece que cada uno se explicara por sí solo. Sin embargo, el sentido común dice que todo está relacionado con todo. Esto quiere decir que cualquier tema que se lleve a nivel de discurso está inmerso en una red de significados. Por ejemplo, en Chile, no se pueden entender los temas de la educación, la salud, la corrupción, etc., sin relacionarlos con lo que está en su génesis en cuanto problema: la pobreza. Este flagelo subyace a todos los tópicos sobre los cuales ayer y hoy se discute como causa y consecuencia.

Si antes la discusión era en un café, en un bar o en el trabajo, actualmente es en el ciberperiódico, donde los lectores dejan el registro de su ideología, de su sistema de creencias, de sus utopías, de sus frustraciones, de sus logros, respecto de sí mismos, de los otros, de 
su experiencia en el mundo. En el diario en línea queda el registro de un pedazo de historia de cada uno de los participantes a través de su opinión que da cuenta ya del discurso dominante impuesto por el sistema neoliberal, ya del discurso de resistencia a dicho sistema.

Así, el objetivo de mi ensayo consiste en dar cuenta de las estrategias argumentativas que utilizan los lectores de blogs de diarios en línea o ciberperiódicos para representar el tópico de la educación en el marco de la pobreza, tema transversal en los comentarios que constituyen el objeto de estudio del presente ensayo. Al mostrar las representaciones discursivas con valor argumentativo, pretendo develar aquellas estrategias lingüísticas que las naturalizan con el fin de perpetuar un estado de cosas. Para ello, desde un marco teóricometodológico sustentado en el Análisis Crítico del Discurso (Fairclough, 1995, 2003; Ramalho e Resende, 2011) y utilizando herramientas de la Gramática Sistémico-Funcional (Halliday, 1994, 2004; Martin y Rose, 2007), describiré los recursos léxico-gramaticales y estrategias argumentativas (Toulmin, 2003), utilizados por los autores de los comentarios con el fin de entregar evidencias de su forma de construir discursivamente su identidad, la de los otros y de su experiencia en el mundo desde su ideología y contexto, siempre en el marco del discurso dominante en el que se inscriben.

\section{Acerca de los ciberperiódicos y de los blogs}

En la actualidad, cada diario en línea en su modalidad multimedia (Yus, 2010) a diferencia de su formato en papel, utiliza todos los recursos que posibilitan una interacción dinámica gracias a recursos tales como el video, audio, imágenes, gráficos, diagramación, publicidad interactiva, etc. (ver páginas de inicio de www.emol.cl, www.cambio21.cl). De este modo, el lector accede a un texto cuya cantidad de información supera lo imaginado, produciendo una especie de infoxicación o intoxicación por exceso de información según Yus, (2010). En este marco, Beyers (2004) señala que cuando hablamos de interacción en los diarios en línea, no solo encontramos los géneros 
usuales (noticias, reportajes, columnas, crónicas, etc.); también encontramos canales de chat, correo electrónico, twitter, foros de opinión, comentarios de blogs, etc. Esta clase de interactividad recibe también el nombre de interacción comunicativa o involucramiento de la audiencia (Beyers, 2004:12; Yus, 2010:96).

Para alejar el riesgo de infoxicación, los lectores cuentan con modos de ejercer control sobre dicha eventualidad: se trata de la capacidad que cada destinatario posee de seleccionar los textos que le interesan y que le permiten satisfacer su necesidad de información y de conocimientos enciclopédicos. El lector puede, tanto elegir entre ingresar a la sección de su interés inmediato (sociedad, política, economía, espectáculo, deportes, servicios, etc.); optar por noticias de último minuto con diversas entradas y vínculos; como optar por acceder a las redes sociales (facebook y Twitter). Asimismo, si es de su interés, puede mirar fotografías novedosas, leer columnas de opinión, ver publicidades atractivas, saber de panoramas culturales, leer revistas periódicas que complementan el diario en línea y una infinidad de textos, todos con el objetivo de satisfacer su interés, curiosidad y avidez no solo por incrementar su acervo, sino también -y tal vez este sea el motivo fundamental- en búsqueda de interacción y solidaridad desde el anonimato.

Los ciberperiódicos presentan ventajas tales como la inmediatez en la transmisión de la información (Castells, 1998, 2003; Yus, 2010); la ubicuidad, es decir, la capacidad de ser leído en cualquier lugar del planeta en que exista la posibilidad de acceso a Internet; la interactividad comunicativa o diálogo con el medio y con otros a través de géneros propios de la red de redes; la multiplicidad de formatos en la misma página o pantágina (García, 2003; Yus, 2010), la actualización constante durante el día; la posibilidad de permanecer en el tiempo, esto es, la capacidad del medio en línea de archivar y permitir la consulta por parte de lectores interesados en determinados temas con fines netamente personales o investigativos, después de su publicación.

En el contexto del ciberperiódico, el blog, es un género discursivo electrónico que se caracteriza tanto por la capacidad de comunicar información como por la posibilidad de retroalimentación, dado que el lector en un rol activo no solo lee, sino que interpreta y comenta 
el mundo representado discursivamente por quien escribe un texto. En otras palabras el blog es una página web que reúne una serie de participaciones realizadas por un autor o bloguero. Cada una de las participaciones está signada por el nombre del bloguero, la fecha, la hora y el número de orden. La última es la que inicia la interacción y la que está en el número uno es la más reciente. (Cebrián y Flores, 2007; Cerezo, 2006; Flores, 2008; Jiménez y Polo, 2007; Orihuela, 2006; Rojas et al., 2007). En la actualidad, el blog permite no solo comentarios sobre el tema que convoca a la comunidad discursiva, sino también sobre el texto de alguno de los participantes en términos individuales, a imitación de los foros de debate.

A continuación, un ejemplo tomado del diario La Segunda on line (www.lasegunda.cl). Se trata de una columna de opinión luego de la cual vienen los comentarios que constituyen el objeto que despierta el interés general:

\section{Melnick, Sergio}

Jueves 09 de Junio de 2011

\section{¿Entienden los estudiantes lo que hablan?}

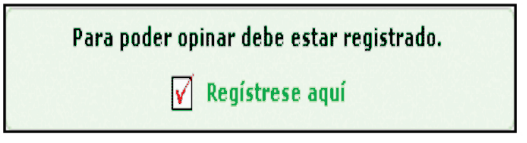

58 Comentarios publicados

\begin{tabular}{|c|c|}
\hline $\begin{array}{r}\text { Posteado por: } \\
\text { Juan Antonio Fuentes Lara } \\
13 / 06 / 2011 \text { 12:01 } \\
{\left[\mathrm{N}^{\circ} 1 \text { ] }\right.}\end{array}$ & $\begin{array}{l}\text { Para mi (sic) la pregunta pertinente para el columnista es: ¿Entiende usted } \\
\text { lo que escribe? } \\
\text { La ignorancia a que se sometió a toda la Sociedad Civil, por los amos de la } \\
\text { República, no permitió, permite ni habría permitido en el futuro: conocer } \\
\text { los que el Estado privado ha impuesto en nuestra Nación. ¿De que" otra } \\
\text { forma puede a colectivo nacional, señalar las injusticias, aberra ciones } \\
\text { aprovechamiento a lo que se le ha sometido des pués de la dictadura: } \\
\text { donde todo se impuso, privatizó, expropio apoderó, sin conocimiento de } \\
\text { los chilenos. La ofensa de su pregunta es propia de la negación de la } \\
\text { realidad del país, que esconde en su estratégica ignorancia }\end{array}$ \\
\hline
\end{tabular}

* Cabe aclarar que se respeta la ortografía original del texto. 
Como se puede observar, el blog de un ciberperiódico es, en síntesis, una página actualizada frecuentemente a través de reflexiones personales, a veces con enlaces a otras páginas, a menudo también con respuestas a otros blogueros. Las participaciones tienden a la brevedad, cuando se trata de ironías, por ejemplo. No obstante, su carácter argumentativo impone un mayor desarrollo cuando se trata de justificar puntos de vista por parte de los integrantes de la comunidad discursiva que realiza el género.

\section{Comentarios, acceso e ideología}

En este ensayo, como he señalado, el objetivo consiste en dar cuenta de las estrategias lingüístico-discursivas y argumentativas que utilizan los lectores de blogs de diarios en línea o ciberperiódicos (Yus, 2010) para representar el tópico de la educación en el marco de la pobreza como tema transversal en los comentarios que constituyen el objeto de estudio. Lo anterior, considerando que dichos comentarios son motivados por diversos temas puestos en la agenda por los mismos medios que dan origen a la interactividad. La pobreza subyace en temas tales como la educación, la delincuencia, la seguridad ciudadana, la familia, la desigualdad social, la precariedad laboral, la corrupción, las políticas para salir del subdesarrollo, las manifestaciones ciudadanas, etc. De ahí la relevancia de analizar las representaciones y argumentos surgidos en el género comentario, como datos que entregan evidencias de modos de construir la realidad discursivamente y de las identidades sustentadas en los sistemas de creencias e ideologías que los participantes asumen en su discurso. En el comentario, los participantes argumentan lo que piensan, sienten y creen respecto de sí, de los otros y del contexto socio-cultural en el cual se encuentran inmersos.

La presente reflexión no pretende configurarse como un estudio sociológico sobre la pobreza y lo que subyace en ella en cuanto problema social (Pardo Abril, 2008), sino en un estudio discursivo acerca de los recursos y estrategias que contribuyen desde la lengua en uso o desde el texto en su contexto, a que se perpetúen estados de cosas, siempre 
desde el discurso de quienes tienen acceso a Internet y que reproducen en el día a día modos de pensar y de construir la realidad desde su posición de poder, cuya acción es más efectiva cuanto más invisible se torna. Para Fairclough (2003), este discurso hegemónico corresponde al poder que se ejerce ideológicamente sobre la sociedad como un todo. Este proceso varía constantemente de acuerdo con el flujo de negociaciones que tengan lugar en una comunidad determinada. Por lo tanto, la organización social se articula sobre un campo de lucha complejo e inestable entre los grupos de poder y los subalternos, cuya principal meta es el dominio del discurso. Un modo de invisibilizar la acción de la ideología es a través del uso de diversos topoi o lugares comunes reproducidos acríticamente y que contribuyen a sustentar las desigualdades (Ramalho e Resende, 2011). Uno de ellos, por ejemplo, es la apelación a la racionalidad con el consecuente descrédito de las formas de presión (marchas, asambleas, paros, etc.).

En síntesis, asumo que el estudio de las representaciones lingüístico-discursivas y los argumentos que los blogueros construyen de sí mismos permitirían tener una visión más integral de quiénes somos como sociedad y como individuos, tomando en cuenta que a través de las identidades asumidas en el "anonimato" del blog se puede decir más de lo que se podría en una interacción cara a cara, pues afloran espontáneamente las ideologías que configuran el espacio desde el cual se opina. Operativamente, la ideología es un concepto inherentemente negativo. Es un instrumento semiótico que supone luchas de poder, es decir, formas de asegurar temporalmente la hegemonía por la diseminación de una representación particular de mundo como si esta fuera la única posible y legítima (Thompson, 2002a; Ramalho e Resende, 2011: 25).

\section{3. ¿Por qué un estudio desde el ACD?}

El estudio del discurso de los comentarios de blogs se enmarca en el Análisis Crítico del Discurso (ACD). Dicho estudio, de acuerdo con (Wodak, 2003: 19), se constituye como una perspectiva teorética 
que aborda el discurso como instrumento de poder, por un lado, y como herramienta que permite la construcción social de la realidad, por otro. En términos de la propia autora, el principal objetivo del ACD consiste en "investigar de forma crítica la desigualdad social tal como viene expresada, señalada, constituida, legitimada, etc., por los usos del lenguaje (es decir, en el discurso)". Esto implica que en un estudio de ACD se busca develar aquellos ámbitos del discurso en donde se vea reflejada una naturalización del abuso o del mal uso del poder en una sociedad determinada. De acuerdo con Wodak (2003), la estructura lingüística se encuentra estrechamente entrelazada con la estructura social. Es por esto que el ACD se interesa por las múltiples formas en que las personas que ejercen el poder, suelen utilizar el lenguaje con la finalidad de cambiar, invertir o manipular el orden social (van Dijk, 2009). Así, para el ACD, son objeto de preocupación aquellas representaciones particulares que pueden contribuir a la distribución desigual del poder, en otras palabras, para llevar a cabo proyectos específicos de dominación o hegemonía (Ramalho e Resende, 2011: 26). Tal es el caso de lo que sucede con el discurso sobre la educación en Chile.

A su vez, van Dijk (2000: 41-43) caracteriza la hegemonía como un acceso especial a actos de habla particulares, proceso que permite lograr la aceptación general por parte de la comunidad discursiva acerca de lo que se propone. De esta forma, la hegemonía "hace que las personas actúen como si ello fuera natural, normal, o simplemente [como si] existiese consenso". Debido a que se trata de una vía exclusiva, gran parte de la comunidad discursiva queda marginada de la posibilidad de conocer, de administrar y de manipular los actos discursivos que permiten obtener el poder. Por esto, un estudio de ACD toma partido por la perspectiva de aquellos actores sociales (van Leeuwen, 2008) que se encuentran subyugados al abuso o mal uso del poder en una sociedad determinada, razón por la cual no han tenido derecho a opinión. En otros términos, estamos ante discursos invisibilizados por un discurso hegemónico que tiene acceso a los medios y que, generalmente tiende a transformar a las víctimas en victimarios al generar "teorías conspirativas". Lo anterior se 
entiende si pensamos que, generalmente, se está construyendo chivos expiatorios para justificar la pobreza, los problemas económicos y políticos, que en la realidad son causados por la codicia, el derroche, y la corrupción, males que al final crean más pobreza y la perpetúan (Beaugrande, 2000, 2008).

\section{ACD y compromiso del analista}

De acuerdo con lo expuesto, los analistas críticos establecen una relación cercana y comprometida con su objeto de estudio, por lo que toman una postura crítica, abierta y determinada con respecto a la investigación (Pardo, 2008). Partiendo de la identificación de problemas sociales, el objetivo consiste en develar discursos que sirven de soporte a estructuras de dominación o que limitan la capacidad de transformación de tales estructuras de acción social (Resende e Ramalho, 2006, 2011). De este modo, la finalidad de un estudio de ACD debe generar cambios sustanciales en la comunidad lingüística, tanto dentro como fuera de la academia, y no servir de mera teorización en torno a una temática en particular. Debido a la finalidad de esta perspectiva, se vuelve esencial adecuarse a los contextos socioculturales desde los cuales se realiza el estudio o, en su defecto, desde donde se focaliza la problemática social y se extrae el corpus a analizar (Pardo, 2008).

Por otro lado, tal como plantea Pardo (2008), una investigación de ACD exige métodos cualitativos de análisis, debido a que el relativismo ontológico del paradigma cualitativo (Guba y Lincoln, 1998, Vasilachis de Gialdino, 2009) admite el ingreso total del investigador y otorga una mirada holística al objeto de estudio. No se simula una imparcialidad científica. Además, esta perspectiva metodológica permite llevar a cabo una revisión constante de todos los aspectos de la investigación, de manera tal que es posible volver sobre la recolección de datos, sobre el análisis realizado y sobre los resultados obtenidos, enriqueciendo el estudio en cada acercamiento. Según Resende (2009) y Pardo (2008), el valor de las teorías y de 
las categorías propiamente lingüísticas emerge de los datos y de los objetivos del análisis. Dicho de otro modo, la Lingüística es utilizada en el análisis del discurso como instrumento para la crítica social. Desde esta perspectiva, en consecuencia, el objetivo de los análisis es la crítica social obtenida por medio del análisis de las instanciaciones discursivas que sirven de soporte a la crítica de problemas sociales. Así, la utilización de categorías lingüísticas se justifica en la medida en que permite al analista:

- explorar la materialización discursiva de problemas sociales en términos de efectos discursivos en las prácticas sociales contextualizadas (y viceversa).

- explorar la vinculación de textos a discursos particulares en la constitución de identidades y en la legitimación de modos de acción.

\section{Práctica social y semiosis}

El papel de los textos en la vida social es relevante en todos los campos de la actividad humana, por ejemplo en la política, en la economía, en el ámbito jurídico, etc. (Fairclough, 2003). Considerando las bases generales del ACD, este autor articula una propuesta de análisis que enfatiza la trascendencia del contexto sociocultural a la hora de describir las características de una lengua determinada. Concibe todas las prácticas sociales como una red interconectada de prácticas de producción que operan en la vida social, sean estas cotidianas, económicas, políticas, culturales, etc. En todas ellas es posible distinguir un elemento semiótico, es decir, un elemento que crea significado.

En otros términos, un estudio de ACD se basa en la identificación de problemas sociales parcialmente discursivos que pueden ser investigados por medio del análisis de textos situados (Chouliaraki y Fairclough, 1999). En consecuencia, no existe práctica social que no sea mediada por el lenguaje; hecho que 
supone una interacción (inter - acción), que implica comunicación, ya sea a través del lenguaje o de cualquier otro tipo de sistema semiótico. Por otro lado, no es posible una acción sin reflexión: la acción social siempre incluye, además de una representación del mundo, una auto-representación de los participantes de la acción respecto de qué es lo que están haciendo. Así, las prácticas sociales integran el lenguaje en una combinación de acción y reflexión que permite la construcción de identidades y de estilos. Las maneras en que actuamos, representamos e identificamos están discursivamente asociadas a las prácticas sociales en que participamos y tienen efectos tanto en la configuración de los textos como en la reproducción / transformación de las mismas prácticas (Fairclough, 2003; Resende e Ramalho, 2006).

En síntesis, para Fairclough (2003), toda práctica incluye los siguientes elementos: una forma relativamente permanente de actuar en lo social; una forma que viene definida en el interior de una estructurada red de prácticas; dominio de la acción e interacción social y reproducción y transformación de estructuras. El ACD se concibe, entonces, como el análisis de las relaciones dialécticas entre la semiosis (proceso por el cual algo funciona como signo) incluido el lenguaje- y otros elementos de las prácticas sociales. $\mathrm{Su}$ objeto de interés lo constituyen los cambios radicales que ocurren en la vida social contemporánea -modo en que figura la semiosis en tales cambios y cambios en la relación existente entre la semiosis y otros elementos sociales pertenecientes a las redes de prácticas, hecho que justifica nuestra indagación en los comentarios de blogs de ciberperiódicos.

Una vez establecidos los elementos que conforman las prácticas sociales, tenemos, por un lado, que un orden social se encuentra compuesto por redes de prácticas, como es el caso del sistema neoliberal imperante (Fairclough 2003; Castells, 2003) Así, este se constituye como el orden social dominante compuesto por una serie de prácticas sociales entre las que tenemos el acceso a Internet por un participante de un blog, opinando según su posición en el mundo sobre un tema polémico y de interés general -en este caso 
la educación como un bien de consumo que debe conectarse con las empresas en tanto hay un componente de inversión ${ }^{2}-$. Entender los procesos discursivos contextualizados en prácticas sociales, implica situarlos en su relación con las personas, las relaciones sociales y el mundo material. En consecuencia, los aspectos discursivos de las prácticas sociales son fundamentales para su configuración.

Sobre esta base, Fairclough (2003: 182) concibe el ACD como un análisis de las relaciones dialécticas presentes entre la semiosis y todos los otros elementos de la práctica social. En contraste con la perspectiva de Wodak (enfoque histórico), Fairclough pone todo el énfasis en el aspecto semiótico y da pie a su propuesta analítica desde él. La semiosis incluye todas las formas de creación de significado, tanto la representación como la autorrepresentación de las prácticas sociales que constituye los discursos. Así, la semiosis supone la forma por medio de la cual se hace visible para un analista del discurso la práctica social. Esto justifica que para él, los discursos correspondan a diversas representaciones de la vida social, las que difieren respecto de la posición de cada actor discursivo. En consecuencia, el ACD está básicamente interesado en las representaciones discursivas -recursos léxicos, semánticos y sintácticos en contexto- (Vasilachis de Gialdino 2003, Montecino, 2008, Pardo, 2010, Molina y D'Angelo, 2010), que dan cuenta, en términos de forma y función, del valor del momento discursivo para llevar a cabo la crítica de las prácticas.

De esta forma, con la finalidad de abordar un estudio sistemáticamente, Fairclough (2003: 184) propone un modelo de cinco pasos, el cual me ha servido como patrón analítico de los datos que sostienen mi análisis. Dichas etapas suponen centrarse en un problema social que tenga un aspecto semiótico; identificar elementos que sostienen el problema y que obstaculizan la posibilidad de abordaje; ver la función del problema en la práctica; identificar las

2. Ver www.cooperativa.cl "requerimos, sin duda, en esta sociedad moderna una mucho mayor interconexión entre el mundo de la educación y el mundo de la empresa, porque la educación cumple un doble propósito: es un bien de consumo" (Sebastián Piñera, Presidente de Chile, 19/07/2011). 
posibles formas de superar los obstáculos y reflexionar críticamente sobre el análisis.

Desde mi perspectiva, los comentarios en los blogs, por un lado, dan cuenta de problemas sociales complejos que se sustentan en argumentaciones y estrategias discursivas (Wodak, 2003) que permiten que no se pueda modificar un determinado estado de cosas; por ejemplo, la defensa de un sistema educativo según el modelo neoliberal que fomenta la desigualdad y el individualismo y que, como consecuencia, genera pobreza. Desde otro ángulo, tenemos el discurso de resistencia que accede a Internet y que pretende por medio del uso estratégico del lenguaje una transformación del orden discursivo.

\section{Tres niveles para abordar un estudio de ACD}

Resende e Ramalho (2006), siguiendo a Fairclough (2003), señalan que un estudio de ACD media entre tres niveles. En primer lugar, se encuentra la práctica social, esto es, el accionar, que corresponde a todo el contexto sociocultural, histórico y político en donde está inserto el o los discursos que son abordados en una investigación. En segunda instancia, el conjunto de textos escritos u orales que son producidos dentro de este marco social constituyen la práctica textual. De esta forma, los textos adquieren las características propias de cada práctica social a la cual pertenecen, por lo que "la circulación, el espacio, el tiempo y lugar que hace que este texto sea este texto y no otro, más su contexto inmediato" corresponde a la práctica discursiva (Pardo, 2002).

\section{ACD y Lingüística Sistémico Funcional}

Para explicar la relación presente entre el orden social y el orden del discurso, Fairclough (2003) toma como referente la Lingüística Sistémico Funcional (LSF) nombre acuñado por M. A. K. Halliday. 
Esta "is a theory of meaning as a choice, by wich a language, or any other semiotic system, is interpreted as networks of interlocking options" (Halliday, 1994: xiv). Es una teoría sistémica porque toma en cuenta el lenguaje desde un punto de vista paradigmático, como un sistema complejo compuesto de tres niveles, a saber, el semántico, el léxico-gramatical y el de la expresión (fonético-fonológico), los cuales no tienen un límite fijo entre sí, sino que se presentan interconectados y se realizan de forma paralela. Por lo tanto, el significado es realizado por la léxico-gramática y esta, a su vez, es realizada por la expresión. En segundo lugar, es una teoría funcional debido a que busca describir cómo se usa la lengua, la cual evoluciona de acuerdo con las necesidades de los seres humanos. Desde esta perspectiva, Halliday (1994: xxxi; 2004) afirma que es el contexto cultural el que determina la naturaleza del código. Asimismo, señala que sin una gramática de base no hay análisis del discurso, sino solo un comentario sobre él, hecho que justifica el uso de la gramática sistémico-funcional.

En consecuencia, pensar en el discurso implica hacer referencia a la ideación, esto significa que debemos centrarnos en el contenido del discurso, en otras palabras, en las secuencias de actividades que realizan los participantes y en cómo estos son descritos y clasificados a través de su experiencia en el mundo. Para ello, son objeto de análisis los participantes (personas, lugares, objetos), los procesos (realizados por verbos) y las relaciones que surgen entre tales elementos con el propósito de dar cuenta de cómo ellos son construidos y se relacionan entré sí a medida que un texto avanza (Martin \& Rose, 2007). Cabe destacar el valor que adquiere la perspectiva desde la cual se presenta una determinada experiencia en el discurso a través de las secuencias de significado. Tanto los procesos como los participantes y las circunstancias asociadas a ellos son los elementos que dentro del texto nos ayudan a determinar desde qué ángulo es presentada una experiencia (material o simbólica), hecho que se puede apreciar en las valoraciones que cada participante emite tanto de las personas como de las acciones que estas realizan. 


\section{La representación de los actores sociales en el texto}

Dependiendo de la posición de los emisores de los textos en el mundo estos representan los hechos de un modo o de otro. Los procesos mentales, materiales, verbales, relacionales, existenciales y de comportamiento (Halliday, 2004), informan de cómo se posicionan los actores en el texto (van Leeuwen, 2008). Para este autor, es fundamental responder las siguientes interrogantes: ¿cómo se representan los actores sociales en el discurso? ¿Cuáles son las alternativas en el discurso para referirse a la gente? y ¿cuáles son los actores sociales relevantes representados? Van Leeuwen (2008) propone un inventario sociosemántico de las formas en que los actores sociales son representados, para luego regresar a la pregunta de cómo se realizan lingüísticamente, entendiendo que cada elección de representación tiene su especificación lingüística o retórica. De este modo, su propuesta considera las categorías relevantes para investigar la representación de los actores sociales en el discurso y a cada una de ellas va asociando los recursos lingüísticos característicos. Para este autor, no todos los actores sociales son incluidos en el discurso. Algunos aparecen representados, otros excluidos de acuerdo a los intereses y propósitos de los emisores y destinatarios del texto. Algunas de estas exclusiones pueden ser 'inocentes' en el sentido de que se excluyen detalles que, se supone, los receptores conocen o se les representa como tópicos irrelevantes; no obstante, también se trata muchas veces de estrategias de creación de imágenes para defender los intereses propios (van Leeuwen, 1996: 38; 2008). Así, la exploración de los movimientos de inclusión y de exclusión de los actores sociales debe complementarse con el análisis de cómo son representados en el discurso. Los actores sociales pueden ser referidos, por ejemplo, como individuos (individualización) o como grupos (asimilación), recurso muy común, por ejemplo, en los discursos de la historia y en el discurso cotidiano del comentario.

Todo lo expuesto, justifica, nuestra indagación en el discurso del comentario. $\mathrm{Su}$ análisis nos permite entender qué hacemos con las palabras, a quiénes, con qué fines, cuál es la ideología dominante, 
qué estrategias utilizamos para dominar y cuáles para resistir; de qué modo incluimos y excluimos (Montecino, 2005); en última instancia, desde nuestro discurso podemos saber cómo percibimos y construimos nuestra percepción sobre la pobreza y sobre la educación en un Chile globalizado y posmoderno, términos sofisticados que nos remiten al neoliberalismo en su esencia.

\section{El problema social}

Durante la década de los ochenta, bajo la dictadura de Augusto Pinochet, el modelo educativo chileno fue objeto de significativas reformas que afectaron directamente la institucionalidad. Los principales focos de dichas transformaciones fueron, por una parte, la consolidación del sistema de subvenciones educacionales, a través de la cual se financia la educación privada y municipal; por otra parte, el afán descentralizador de la gestión del estado, que se tradujo en el traspaso a los municipios de todos los establecimientos educacionales dependientes del gobierno central. Así, se instaló un sistema en el cual el Ministerio de Educación (MINEDUC) aporta una subvención mensual por alumno que asiste a clases en las escuelas, sean éstas municipales o particulares, a las que los padres eligen enviar a sus hijos, bajo el pretexto de que cada familia elige libremente el tipo de establecimiento y de educación, según su sistema de creencias y valores.

De este modo, de un sistema en que el Estado asumía toda la responsabilidad respecto de la educación como un derecho, se pasó a uno que define la educación como un bien de consumo. Tanto es así que el problema no afecta solo a los estudiantes de enseñanza básica y media, sino también a los de educación superior (universitarios, institutos y centros de formación técnica, etc.). Los aranceles para poder llevar a cabo el sueño de la movilidad social por la vía educacional son tan altos, que el estudiante apoyado por su familia debe solicitar préstamos que le permitan solventar los gastos de los años que dura la carrera. Al término de esta, la ingente deuda contraída con el Estado o 
con un banco supone la devolución de los fondos invertidos. Solo que ya no se trata de devolver lo que se recibió en calidad de préstamo, sino de pagar enormes cifras aumentadas por los intereses, que en muchos casos sirvió para pagar una carrera en una universidad o instituto de dudosa calidad. El mercado laboral no perdona: depende de donde el sujeto estudió si accederá al mundo del trabajo exitosamente o no. Así,

Los problemas centrales que tienen los estudiantes tienen que ver con los elevados aranceles universitarios que en términos relativos al PIB per cápita son los más altos del mundo. La tasa de crecimiento de los aranceles universitarios es muy por sobre el IPC, si uno mira un período de 12 años los aranceles en promedio en todas las universidades, con y sin fines de lucro, suben en promedio un 5,5\% real. Eso genera una brecha creciente en las becas y en los créditos que están asociados a los aranceles de referencia que se reajustan según el IPC.

Con un hijo en la universidad se incide en el gasto familiar más de un $40 \%$ (...) Esto genera un alto nivel de morosidad, más de un $40 \%$ de los estudiantes del Fondo Solidario en las universidades del $\mathrm{Cruch}^{3}$ están morosos y un porcentaje similar existe entre los estudiantes del Crédito con Aval del Estado (CAE) ${ }^{4}$.

En consecuencia, de acuerdo con lo expuesto, las demandas de los estudiantes de nivel superior exigen una educación de calidad, igualitaria y gratuita y el fin del lucro, mientras los secundarios piden que la administración de sus escuelas y liceos deje de ser municipalizada y retorne al Estado. ${ }^{5}$

3. CRUCH, sigla que alude al Consejo de Rectores de las Universidades Chilenas.

4. http://www.cieplan.org/noticias/detalle.tpl?id=166, 08/09/2011.

5. “Toda persona tiene derecho a la educación. La educación debe ser gratuita, al menos en lo concerniente a la instrucción elemental y fundamental. La instrucción elemental será obligatoria. La instrucción técnica y profesional habrá de ser generalizada; el acceso a los estudios superiores será igual para todos, en función de los méritos respectivos. La educación tendrá por objeto el pleno desarrollo de la personalidad humana y el fortalecimiento del respeto a los derechos humanos y a las libertades fundamentales; favorecerá la comprensión, la tolerancia y la amistad entre todas las naciones y todos los grupos étnicos o religiosos; y promoverá el desarrollo de las actividades de las Naciones Unidas para el mantenimiento de la paz. Los padres tendrán derecho preferente a escoger el tipo de educación que habrá de darse a sus hijos...” Declaración Universal de los Derechos Humanos, Art. 26. 


\section{Representaciones discursivas del problema social}

Las representaciones que se reproducen en el discurso hegemónico cotidiano respecto de la educación, dan cuenta de una perspectiva cuyo referente es la empresa. Veamos los recursos léxicogramaticales marcados en negrita:

\begin{tabular}{|rr|}
\hline Posteado & A pesar de lo bien que marcha la economía, a pesar \\
por: & de que se está administrando mejor el Estado, a pesar de que \\
Francisco & no se han registrado nuevos Chile recortes, MOP Gate, EFE, \\
Martínez & Indap, Injuv*, etc. A pesar de todo eso, hay marchas. Una tras \\
$03 / 08 / 2011$ & otra. Todo orquestado por sectores con intereses particulares y \\
$09: 39$ & muy distintos del Bien Común: el Colegio de Profesores, cier- \\
{$\left[\mathrm{N}^{\circ} 15\right]$} & tos sectores de estudiantes, etc., ambos, casualmente, ligados \\
& al PC. iOh, sorpresa! \\
& Se pide nacionalización del cobre para financiar la \\
educación (iQué brutalidad más grande! ¿Sabrán acaso los \\
niñitos, las consecuencias en la inversión que ello produjo por \\
más de 15 años en Chile?). Se pide aumento de platas, cuan- \\
do entre 2008 y 2009 se aumentaron 4.000 millones de US\$ \\
y ahora otro aumento similar. Se pide de todo, menos lo que \\
realmente importa: rigor, disciplina, trabajo, valores, princi- \\
pios y eficiencia en la utilización de recursos. \\
La plata es secundaria. Necesaria, pero secundaria. Lo \\
primordial es lo anterior, aunque el PC y los estudiantes, lle- \\
no de ideologías movidas por pasiones y nula racionalidad, \\
piensen otra cosa. \\
Me recuerda al Chile previo al 70.
\end{tabular}

Alusiones directas a casos de corrupción durante los últimos gobiernos de la Concertación de Partidos por al Democracia.

Discursivamente, se presenta el problema de modo tal, que pareciéramos estar participando de una negociación colectiva en términos netamente gremiales, cuando de lo que se trata es de recuperar, políticamente, el concepto de la educación como derecho, situación que supone cambios estructurales. El proceso pedir + objeto directo (nacionalización del cobre, aumento de platas, todo), aparece valorado negativamente: iQué brutalidad más grande!; los 
actores sociales demandantes son representados como niñitos y sus peticiones en general como factores de poca importancia en términos administrativos empresariales.

Argumentativamente, la representación valorativa que se construye respecto de Chile sobre la base de lo que sus finanzas indican es positiva, no obstante, la conclusión es negativa, pues

a) A pesar de lo bien que marcha la economía,

b) a pesar de que se está administrando mejor el Estado, valoración positiva

c) a pesar de que no se han registrado nuevos Chile recortes, MOP Gate, EFE, Indap, Injuv ${ }^{6}$, etc.

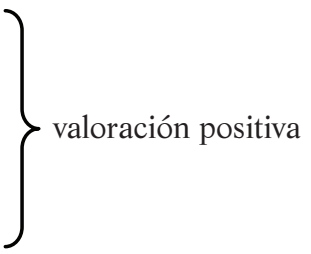

d) A pesar de todo eso,

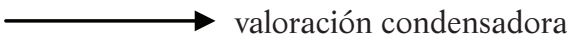
positiva

e) hay marchas. Una tras otra.

Valoración negativa

f) Todo orquestado por sectores con intereses particulares y muy distintos del Bien Común: el Colegio de Profesores, ciertos sectores de estudiantes, etc., ambos, casualmente, ligados al PC. iOh, sorpresa!

conclusión negativa

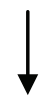

comunismo

De acuerdo con lo expuesto, la tesis sostenida por el autor del posteo desde su anonimato es que el país está bien y las marchas son responsabilidad del comunismo organizado. La educación como señalara el Presidente de la República es un bien de consumo y si hay algún problema, es porque los estudiantes no entienden que "nada es gratis en esta vida, alguien tiene que pagar"7. No obstante, desde mi perspectiva, las movilizaciones ciudadanas de estos últimos cinco

6. Alusiones directas a casos de corrupción durante los últimos gobiernos de la Concertación de Partidos por al Democracia que gobernara entre 1990 y 2010.

7. http://www.elmostrador.cl/noticias/pais/2011/08/11/pinera-sobre-educacionnada-es-gratis-en-esta-vida-alguien-lo-tiene-que-pagar/ 
meses no son "orquestadas" por el comunismo ni por partido político alguno, pues carecen de representatividad en el universo juvenil. La causa de las movilizaciones es la educación misma entregada en estos últimos quince años desde un proyecto solidario de sociedad que al parecer parece extinguirse: los estudiantes son educados y, en consecuencia, han aprendido a cuestionar el mundo en el que viven; saben qué desean como modelo de sociedad y, con ello, saben que merecen un mejor sistema educativo para todos, no solo para un grupo privilegiado.

El posteo anterior se plantea como una síntesis de los argumentos y de las representaciones discursivas de los actores sociales participantes. En términos argumentativos, se reitera que la causa del problema es el comunismo que necesita que exista conflicto y odio y, por ningún motivo, libertad de enseñanza. Así, el problema educacional chileno no es tanto sistémico, como político. Los actores sociales que están a favor de las marchas de los jueves, son tontos que se suman a la mayoría sin importar la racionalidad de sus planteamientos; sus líderes son niñitos que nada saben de derechos y deberes. La niñita Vallejo ${ }^{8}$ deja entrever -a través de sus declaraciones- el antisocial pensamiento de la izquierda comunista. Los dos dirigentes carismáticos físicamente atractivos y muy bien instruidos en retórica, forman parte de una estrategia típica del Comité Central de Partido Comunista y de los socialistas para convencer a permeables estudiantes, designados en el ámbito privado como tontos útiles, cuyo fin último es conseguir algún muertito durante las protestas con el fin de victimizarse $y$ convertir a los protectores de la sociedad, nuestros carabineros, en genocidas y atropelladores de los derechos humanos. Camila Vallejo y Giorgio Jackson son representados como dos peluzones ${ }^{9}$ (sic), dos soldados marxistas entrenados para confundir; se trata de dos tontines que en su momento van a ser sustituidos por otros dos o tres tontos ignorantes resentidos que, ni siquiera sabrán por qué marchan. Son adolescentes iluminados que forman parte de una

8. Líder del movimiento estudiantil universitario.

9. En el español de Chile, adolescentes rebeldes y marginales. 
generación de niños pataleteros ${ }^{10}$ e intransigentes que representan al Partido Comunista. Las autoridades no pueden ser pauteadas por unos pergenios chicos que solo tienen el poder del caos, la prepotencia máxima. Es imposible que dos farsantes se entreguen en cuerpo y alma a promover el desorden entre cien picantes que tocan el bombo y tiran piedras, movidos por el rencor y el revanchismo, desparramados en calles y lugares públicos, por la mano que mece la cuna...!!!

Cómo vemos, los recursos lingüístico-discursivos utilizados en los comentarios de los lectores de ciberperiódicos sobre el mundo representado en los textos, son altamente valorativos. Esto supone que tales expresiones no son solo apreciaciones personales, sino aspectos verdaderamente interpersonales, cuyo fin último consiste en emitir una opinión con el fin de provocar una respuesta de solidaridad y de sentido de pertenencia por parte del destinatario en términos de identidad (Martin, 2000: 142). A través de las valoraciones, quien emite el comentario plantea su ideología y organiza el texto con el fin de lograr, solidaridad e identidad. El hecho de identificar lo que el autor piensa nos entrega datos que trascienden lo netamente personal. Esto porque todo acto de valoración está dirigido a reproducir un determinado sistema que subyace en el texto. En otras palabras, al identificar lo que piensa el autor, se revela no solo su ideología, sino la de la comunidad de práctica en que se ha producido el texto ${ }^{11}$. Solo de ese modo, podemos explicarnos el poder que puede tener dicho texto y las valoraciones inscritas en él como instrumentos de manipulación de los lectores con el propósito de persuadirlos a ver la realidad de un modo específico. En consecuencia, lo que opinan los autores de los comentarios no solo es información en el sentido más general del

10. En el español de Chile, caprichosos.

11. Quienes acusan a los líderes del movimiento estudiantil como altamente ideologizados, falazmente intentan hacer creer que su posición carece de ella, no obstante ser defensores del neoliberalismo. Mientras el movimiento intenta luchar por cambios estructurales en la educación, los opositores defienden el mercado, el crédito, el endeudamiento, el lucro, la inequidad social y educativa, como una forma de perpetuar la pobreza estructural. 
término, sino que implica que algo ocurrió y que existen opiniones sobre ello; también supone la clave para acceder a la comprensión de las argumentaciones y sobre cómo están organizadas desde una perspectiva que pone en evidencia la posición del hablante desde el afecto, el grado de compromiso y la apreciación.

En nuestros materiales, la representación de los actores sociales surge del afecto y de la emoción que cada participante en el blog manifiesta en su discurso: son tontos que se suman a la mayoría sin importar la racionalidad de sus planteamientos; se construye la imagen del ellos irracional v/s yo racional, que nos conecta con la inseguridad (Oteíza, 2006). Asimismo, emerge la expresión del juicio que se traduce en explicitar una evaluación sobre otra persona y sus acciones en la medida que se transgrede lo socialmente esperado en determinados comportamientos. Respecto de Camila Vallejo y Giorgio Jackson, por ejemplo, los comentarios insisten en valoraciones negativas que los construyen como niñitos que nada saben de derechos y deberes. Las valoraciones que emergen en los comentarios apuntan básicamente a la sanción social. Esto, dado que ninguno de los dos representantes del movimiento estudiantil cabe dentro del canon conservador y pro neo liberalismo que esperan los comentaristas del ciberperiódico, cuya ideología está al servicio del modelo. Discursivamente, el ataque a los líderes del movimiento estudiantil universitario es una estrategia para desprestigiar un modelo opuesto al neoliberal que en Chile ha generado la mayor desigualdad en su historia; el nivel de pobreza y endeudamiento se ha intensificado a pesar de los buenos índices de éxito de la economía que crece, pero cuya distribución no dice lo mismo. La educación, de acuerdo con el orden establecido por Pinochet, y que fue imposible modificar durante los gobiernos de la Concertación, crea esclavos cuya deuda abarca no solo a quien se educa, sino a la familia entera. Esta es la razón por la cual quienes dirigen el movimiento exigen educación gratuita y de calidad, no para algunos, sino para todos, con el objetivo último de acceder a las oportunidades no por factores económicos, sino por derecho. 


\section{Falacias}

Respecto de la argumentación, cabe señalar que la más frecuente es aquella que no va en contra de las ideas, sino en contra de la persona. Veamos el siguiente cuadro:

\begin{tabular}{|c|c|}
\hline $\begin{array}{l}\text { Con estudiantes y profesores llamando a } \\
\text { incendiar el país porque no se hace todas y } \\
\text { cada una de las cosas que desean no es mu- } \\
\text { cho más lo que se puede hacer }\end{array}$ & $\begin{array}{l}\text { Falacia ad hominem: agenti- } \\
\text { vidad negativa de los actores } \\
\text { sociales demandantes. Topoi: } \\
\text { amenaza. }\end{array}$ \\
\hline $\begin{array}{l}\text { Ya esta bueno que estos Pergenios Revolu- } \\
\text { cionarios, se crean con el derecho de dejar } \\
\text { la cagada }+1 \text {, siendo que con suerte saben } \\
\text { sumar y restar. }\end{array}$ & $\begin{array}{l}\text { Falacia ad hominem: Agenti- } \\
\text { vidad negativa de los actores } \\
\text { sociales demandantes. Topoi: } \\
\text { amenaza. }\end{array}$ \\
\hline $\begin{array}{l}\text { Váyanse a estudiar y entiendan que las úni- } \\
\text { cas cosas gratis, son las que se ganan con } \\
\text { esfuerzo. Todo el resto cuesta plata. }\end{array}$ & $\begin{array}{l}\text { Falacia ad hominem: Acto dis- } \\
\text { cursivo de mandato que per- } \\
\text { mite construir una identidad } \\
\text { irracional de los actores socia- } \\
\text { les demandantes. Topoi: pro } \\
\text { bono público. }\end{array}$ \\
\hline $\begin{array}{l}\text { Por sobre todo, es necesaria la formación } \\
\text { moral que solo puede dar la fe verdadera. } \\
\text { Esos que quieren un educación "laica", han } \\
\text { precipitado todos los problemas que hoy ve- } \\
\text { mos en la educación y en la sociedad actual. }\end{array}$ & $\begin{array}{l}\text { Falacia ad hominem: Agenti- } \\
\text { vidad negativa de los actores } \\
\text { sociales que no adhieren al } \\
\text { catolicismo, marco de refe- } \\
\text { rencia de la racionalidad y los } \\
\text { principios y valores socialmen- } \\
\text { te aprobados por el mundo } \\
\text { conservador. Topoi: responsa- } \\
\text { bilidad. }\end{array}$ \\
\hline $\begin{array}{l}\text { Tenemos drogadicción, embarazo adoles- } \\
\text { cente, alcoholismo, y violencia pendenciera } \\
\text { desatada en las aulas producto precisamen- } \\
\text { te de la exigencia de una educación carente } \\
\text { de moral y principios por parte de algunos } \\
\text { "iluminados" que desearían ver al mundo } \\
\text { ardiendo por todos sus costados. }\end{array}$ & $\begin{array}{l}\text { Falacia ad hominem: agen- } \\
\text { tividad negativa de los acto- } \\
\text { res sociales. No responden a } \\
\text { los cánones impuestos por el } \\
\text { mundo conservador propio de } \\
\text { la clase alta. Topoi: la realidad } \\
\text { se impone. }\end{array}$ \\
\hline
\end{tabular}




\begin{tabular}{|c|c|}
\hline $\begin{array}{l}\text { Al ser estas marchas destructoras y con per- } \\
\text { manentes tomas, bloqueos de caminos, etc. } \\
\text { etc. con propuestas absolutamente intransi- } \\
\text { gentes por los estudiantes, lideradas directa- } \\
\text { mente por el Partido Comunista con Jaime } \\
\text { Gajardo y Camila Vallejo, con su carrera } \\
\text { congelada, es absolutamente esperable que } \\
\text { esto inicie prontamente una cruda violencia } \\
\text { entre los chilenos. }\end{array}$ & $\begin{array}{l}\text { Falacia ad hominem: agenti- } \\
\text { vidad negativa de los actores } \\
\text { sociales, personalizada en dos } \\
\text { de ellos como responsables de } \\
\text { la violencia. Topoi: amenaza. }\end{array}$ \\
\hline $\begin{array}{l}\text { De nada sirve gritar o demandar mejorías del } \\
\text { contexto si es que los educadores, los estu- } \\
\text { diantes y sus familias no mejoran en su ac- } \\
\text { tual calidad. }\end{array}$ & $\begin{array}{l}\text { Falacia ad hominem: represen- } \\
\text { tación discursiva negativa de los } \\
\text { actores sociales: ellos no cum- } \\
\text { plen con las expectativas que } \\
\text { supone el discurso dominante. } \\
\text { Topoi: pro bono público. }\end{array}$ \\
\hline
\end{tabular}

Como señalábamos, es el ataque discursivo - valorativo a las personas lo que sustenta el argumento de quien emite su comentario en el blog. Todo no pasa de ser una operación desde el discurso dominante en contra de quien está en posición desvalorizada. La legitimación ideológica proviene de la construcción del yo como racional, cuyos intereses remiten a preocupaciones universales que se inscriben en historias de un pasado reciente (Golpe de Estado de 1973 y sus consecuencias): nos referimos, específicamente, a la idea de desorden y caos generado en la época aludida por grupos de extrema derecha. Asimismo, otras formas de legitimar el discurso del grupo dominante apela a la fragmentación: unos pocos individuos o un grupo son identificados como amenaza o enemigo, con el fin de naturalizar fundamentalmente los siguientes argumentos:
a) la violencia bajo la amenaza de un nuevo 11 de septiembre del' 73
b) el endeudamiento extremo, pues todo se paga, nada es gratis y, por último,
c) la consecuencia lógica: aceptación del estado de pobreza por miedo y deuda.


Tanto la agentividad negativa de los actores sociales como la amenaza que representan se construye por medio de recursos lingüístico-discursivos tales como:

- uso de procesos materiales (incendiar, dejar la cagada +1 , precipitar); procesos mentales (váyanse a estudiar, entiendan, con suerte saben + complemento, desear ver + objeto directo).

- $\quad$ uso reiterado de adjetivación intensificadora: pergenios revolucionarios, formación moral, fe verdaderav/s educación laica, educación carente de moral y principios, algunos "iluminados", mundo ardiendo, marchas destructoras, bloqueos de caminos, propuestas absolutamente intransigentes, cruda violencia entre los chilenos.

- uso de nombres cuya referencia alude a aspectos negativos de la realidad que podrían ser considerados causa y/o efecto de prácticas sociales erradas por parte de quienes demandan una educación justa y de calidad: drogadicción, embarazo adolescente, alcoholismo, y violencia pendenciera desatada en las aulas.

- uso de marcadores discursivos y de operadores pragmáticos intensificadores: 'Ya esta bueno que estos Pergenios Revolucionarios', 'siendo que, con suerte saben sumar y restar' (valor negativo), 'Por sobre todo, es necesaria la formación moral', 'producto precisamente de la exigencia de una educación carente de moral', 'con propuestas absolutamente intransigentes', 'lideradas directamente por el Partido Comunista' es absolutamente esperable que esto inicie prontamente una cruda violencia entre los chilenos'.

- En consecuencia, los argumentos construidos con el objeto de mantener el estado de cosas, actúan discursiva e ideológicamente sobre los otros como un abuso de poder sustentado en el miedo y la amenaza constante. Discursivamente, la realidad se presenta en forma maniquea: la generalización supone que todo aquel que protesta y manifiesta su adhesión al movimiento estudiantil, 
es comunista y propiciador de la violencia; eso, antes que demandante de modificaciones estructurales que signifiquen la restitución de la educación como un derecho y no como un bien de consumo.

\section{Consideraciones finales}

Como se puede observar, el discurso que motiva estas reflexiones se inscribe en una red interconectada de prácticas de producción que operan en la vida social que implica tanto la reproducción del discurso cotidiano, la historia que le sirve de marco y las condiciones económicas, políticas y culturales que la constituyen. Dicha red no es sino un elemento complejo que crea significado, considerándolo como un elemento semiótico. La práctica social del comentario en los ciberperiódicos integra el lenguaje en una combinación de acción y de reflexión que permite la visibilización de identidades naturalizadas en el contexto en el cual las prácticas sociales se realizan. No debemos olvidar que el modo en que actuamos, representamos e identificamos discursivamente nuestra experiencia en el mundo, están asociadas a las prácticas en las cuales participamos. Asimismo, no podemos desconocer su influjo, tanto en la configuración de los textos como en la reproducción y/o transformación de determinadas estructuras sociales.

Así, tenemos que los autores de los comentarios en estudio a través de su discurso construyen su identidad conservadora, reproduciendo diversas falacias sustentadas en diversos topoi (Wodak, 2003), por ejemplo, el de la historia magistra vitae que nos enseña que una acción concreta tiene consecuencias concretas, hecho que condicionará la realización o no de determinadas acciones en situaciones específicas. Por otra parte, también a través de los comentarios los autores apelan al topos del pro bono público (lo que expongo es la verdad y la hago pública por el bien de todos); al topos de la amenaza; al topos de la responsabilidad; al topos del peso de la realidad, etc. El recurso de los topoi sirve a los comentaristas (yo), en cuanto configuración de 
una estrategia, para intentar persuadir falazmente al ellos acerca de las ventajas de un proyecto social y educacional que ha fallado y que exige modificaciones estructurales.

Metodológicamente, hemos identificado una práctica social que sirve de referente a nuestras reflexiones: el comentario en ciberperiódicos. Luego de ello, hemos descrito el problema social que posee, por cierto, aspectos semióticos (la necesidad de una educación de calidad, igualitaria, gratuita y sin fines de lucro). Así también, hemos dado cuenta de los elementos que lo sostienen discursivamente: el miedo y la amenaza bajo el pretexto de construir un futuro digno y justo en virtud del bien público. Lo anterior, construido a través de una selección léxico-gramatical intensificada, que transforma a las víctimas en victimarios en un contexto conspirativo en el cual el discurso sirve de soporte a estructuras de dominación.

Los actores sociales que marchan por las calles se representan como desvalorizados en términos éticos; en cuanto agentes, son negativos y destructores del orden público; intelectualmente, son irracionales, simples 'tontos útiles' que construyen una cara visible del comunismo que corrompe y genera el odio de clases.

En consecuencia, tanto los argumentos como los recursos lingüístico-discursivos entregan evidencias de que quienes comentan en el blog lo hacen desde su posición de poder en términos de acceso, repitiendo estratégicamente los mismos topoi registrados tanto en el cine, en la TV, en la prensa escrita, en la historia oficial, en fin, en toda práctica social cultural con el fin de ejercer control sobre quienes desde la precariedad se manifiestan en las calles por una educación gratuita de calidad y sin fines de lucro. Treinta años se ha tardado el sistema neo liberal en asumir que la educación es un bien de consumo (Piñera, 19/07/2011); cabe preguntarse ¿cuánto tardará en volver a ser un derecho? Por lo pronto, respecto de la gratuidad demandada por los estudiantes, el presidente Piñera sostiene: "no hemos asumido la causa de educación gratuita para todos por dos razones: Primero porque Chile no está hoy día posibilitado de alcanzar esa meta, pero en segundo lugar porque no es justo que con los impuestos que pagan los más pobres de nuestro país estemos financiando la educación de los 
más ricos, por eso, a pesar de los cantos de sirena nuestro compromiso hasta siempre con los más pobres y la clase media que son los que realmente requieren ese apoyo del Estado". Frente a esta falacia, surge el argumento del periodista Fernando Paulsen ${ }^{12}$ (ADN Radio), quien señaló en uno de sus programas: "El país está secuestrado por tres mil o cuatro mil personas verdaderamente ricas que difunden la ideología de que la universidad gratis es subsidiar a los más ricos. Lo que realmente quieren evitar es que les suban los impuestos, porque para ellos es más barato pagar la universidad que contribuir realmente de acuerdo a sus ingresos”.

Un cambio estructural, como el que señala Paulsen y en el cual insisten los líderes estudiantiles, significa un golpe al flagelo de la pobreza que tiende a perpetuarse a través de discursos populistas falaces.

Recebido em: 20/09/2011

Aprovado em: 24/10/2011

lesanton@gmail.com

\section{Referencias Bibliográficas}

BEAUGRANDE, R. La saga del análisis del discurso. En T. van Dijk (comp.) El discurso como estructura y proceso. Barcelona: Gedisa, 2000, p. 67-106.

BEYERS, H. Interactivity and on line newspapers. A case study on discussion boards. Convergence, 10 (4), 2004, p. 11-20.

CABRERA, M. Convivencia en la prensa escrita y la prensa on line en su transición hacia el modelo de comunicación multimedia. Estudios sobre el mensaje periodístico, 7. 2001. [http://www.ucm.es/info/periol/Period_I/ EMP/Numer_07/7-4-Comu/7-4-01.htm].

12. El periodista Fernando Paulsen dirige en ADN Radio el programa La prueba de $\mathrm{ADN}$; en Chilevisión participa en el programa dominical nocturno Tolerancia Cero. Debido a su trabajo riguroso es uno de los profesionales de la información con mayor credibilidad. 
CASTELLS, M. La era de la información. Madrid: Alianza, 2003.

CEBRIÁN, M. y J. Flores (eds.). Blogs y periodismo en la red. Madrid: Fragua, 2007.

CEREZO, José M. (coord.) La blogosfera hispana: pioneros de la cultura digital. Fundación France Telecom. Madrid: 2006.

CHOULIARAKI, L.; FAIRCLOUGH, N. Discourse in late modernity: rethinking critical discourse analysis. Edinburgh: University Press, 1999.

FAIRCLOUGH, N. Discourse and Social Change. Cambridge: Polity, 1995.

FAIRCLOUGH, N. El análisis crítico del discurso como método para la investigación en ciencias sociales, en Ruth Wodak y Michael Meyer, Métodos de análisis crítico del discurso. Barcelona: Gedisa, 2003.

FLORES, J. (ed.). Blogalaxia y periodismo en la red. Estudios análisis y reflexiones. Madrid: Fragua, 2008.

FOUCAULT, M. El orden del discurso. Barcelona: Tusquest, 1970.

GARCÍA, J. La configuración tecnológica, lingüística y comunicativa del correo electrónico. Linguax 4, 2003, p. 3 - 17.

GUBA E.; LINCOLN, Y. Competing Paradigms in Qualitative Research. En N. Denzin y Y. Lincoln (eds.) Handbook of Qualittative Research. Thousand Oaks, California: Sage, 1994.

HALLIDAY, M.A.K. An Introduction to Functional Grammar. (2nd. ed.) London: Edward Arnold, 1994.

HALLIDAY, M.A.K. An Introduction to Functional Grammar. (3rd. ed., revised by C. Matthiessen.) London: Edward Arnold, 2004.

JIMÉNEZ, R.; POLO, F. (eds.). La gran guía de los blogs 2008, El Cobre Ediciones, Barcelona, 2007.

MARTIN, J. R. Beyond Exchange: Appraissal System in English. En S. Hunston y G. Thompson (eds.), Evaluation in Text. Oxford: Oxford University Press, 2000, p. 142-175.

MARTIN, J. R.; ROSE, D. Working with Discourse. Meaning beyond the clause. London: Continuum, 2007.

MOLINA, L.; D’ÁNGELO, G. Vivir sin agua a metros del obelisco: la representación de los pobres en corpus audiovisual. En Montecino, L. (ed.) Discurso pobreza y exclusión en América Latina. Santiago: Cuarto Propio, 2010, p. 229 - 44. 
MONTECINO, L. Inmigración y exclusión en un foro chileno de internet: análisis crítico de representaciones discursivas. En Harvey A. (Comp.) En torno al discurso. Contribuciones de América Latina. Santiago: Ediciones Universidad Católica de Chile, 2005, p. 272 - 287.

ORIHUELA, J. La revolución de los blogs. Cuando las bitácoras se convirtieron en el medio de comunicación de la gente. Madrid: La Esfera de los Libros, 2006.

OTEÍZA, T. El discurso pedagógico de la historia. Santiago: Frasis, 2006.

PARDO ABRIL, N. ¿Qué nos dicen? ¿Qué vemos? ¿Qué es... pobreza? Análisis crítico de los medios. Bogotá: Antiquus, 2008.

PARDO, L.; BUSCAGLIA, V. Señalados por el lenguaje: una historia de pobres y de locos. Análisis crítico de la Deíxis en el discurso de personas delirantes. En Montecino, L. (ed.) Discurso pobreza y exclusión en América Latina. Santiago: Cuarto Propio, 2010, p. 53-69.

PARDO, M.L. (ed.). Una metodología para la investigación lingüística del discurso. En M. Pardo (ed.) El discurso sobre la pobreza en América Latina. Santiago de Chile: Frasis, 2008, p. 55-78.

RAMALHO, V.; RESENDE V. M. Análise de discurso (para a) crítica: o texto como material de pesquisa. Campinas, SP: Pontes, 2011.

RESENDE, V. M.; RAMALHO, V. Análise de discurso crítica. Sao Paulo: Contexto, 2006.

RESENDE, V. Análise de discurso crítica e realismo crítico. Implicações interdisciplinares. Campinas: Pontes, 2009.

ROJAS, O. et al. Blogs. La conversación en Internet que está revolucionando medios, empresas y ciudadanos. Madrid: ESIC, 2005.

THOMPSON, J. Ideology and Modern Culture: Critical Social Theory in the Era of Mass Communication. California: Stanford University Press, 1990.

TOULMIN, S. Los usos de la argumentación. Barcelona: Península, 2007.

VAN DIJK, T. Ideología. Una aproximación multidisciplinaria. Barcelona: Gedisa, 2000.

VAN DIJK, T. Discurso y poder. Barcelona: Gedisa, 2009.

VAN LEEUWEN, T. Representation of social actors, en C. Caldas Couldthard y M. Couldthard (eds.). Texts and Practices. Reading in Critical Discourse 
Analysis. Londres: Routledge, 1996, p.32-83.

VAN LEEUWEN, T. Discourse and Practice. New Tools for Critical Discourse Analysis. Oxford: Oxford University Press, 2008.

VASILACHIS DE GIALDINO, I. Pobres, pobreza, identidad y representaciones sociales. Barcelona: Gedisa, 2003.

VASILACHIS DE GIALDINO, I. (Coord.) Estrategias de investigación cualitativa. Barcelona: Gedisa, 2009.

WODAK, R. ¿De qué trata el análisis crítico del discurso (ACD). Resumen de su historia, sus conceptos fundamentales y sus desarrollos. En Wodak R. y M. Meyer (2003). Métodos de análisis crítico del discurso. Barcelona: Gedisa, 2003.

YUS, F. Ciberpragmática 2.0: nuevos usos del lenguaje en Internet. Barcelona: Planeta, 2010. 